\title{
A case series of ocular involvement in bullous pemphigoid: clinical features, management, and outcomes [version 1; peer
}

\section{review: 2 approved]}

\author{
Anahita Kate (D) , Swapna Shanbhag (D2), Pragnya Rao Donthineni2, \\ Sayan Basu (102,3
}

${ }^{1}$ The Cornea Institute, L V Prasad Eye Institute, KVC Campus, Vijaywada, Andhra Pradesh, India

${ }^{2}$ The Cornea Institute, L V Prasad Eye Institute, Hyderabad, Telangana, India

${ }^{3}$ Prof. Brien Holden Eye Research Centre, L V Prasad Eye Institute, Hyderabad, Telangana, India

V1 First published: 25 Nov 2021, 10:1201

https://doi.org/10.12688/f1000research.75120.1

Latest published: 31 Jan 2022, 10:1201

https://doi.org/10.12688/f1000research.75120.2

\section{Abstract}

Ocular involvement in cases of bullous pemphigoid is rare and when present, the signs are usually subtle and in the form of fine tarsal scarring and dry eye disease. The current report aims to describe the clinical features and management protocols in a series of cases with aggressive ocular manifestations at presentation.

All cases of bullous pemphigoid seen between 2017 and 2020 were included in this retrospective case series. Data regarding the clinical features, treatment administered, and outcomes was collected. Five cases ( $n=10$ eyes) of bullous pemphigoid disease with ocular involvement were included. All eyes had significant cicatricial conjunctival changes in the form of symblephara, inferior forniceal shortening, and tarsal conjunctival scarring. Conjunctival granulomas were present in 3/10 eyes. Corneal involvement in the form of punctate keratitis was present in all eyes while $4 / 10$ eyes had an epithelial defect as well. The management of these cases involved topical therapy with corticosteroids and lubricants ( $n=10$ eyes) while pulse doses of intravenous methyl prednisolone were administered in $5 / 5$ cases. Pulse intravenous cyclophosphamide was supplemented in $2 / 5$ cases. Adequate control of the disease was noted in 3/5 cases while one case had a recalcitrant form of the disease and developed a dermalised ocular surface in both eyes. The last patient was lost to follow up during the course of therapy.

Bullous pemphigoid can present with an aggressive form of cicatrizing conjunctivitis similar to other variants of autoimmune blistering disorders and must be considered as a differential in cases presenting with ocular cicatricial disease. Long-term intensive immunosuppression is required for the management of these cases to preserve the visual function and the integrity of the globe.

\section{Open Peer Review}

Approval Status

1 2

version 2

(revision)

31 Jan 2022

version 1

25 Nov 2021

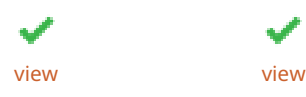

1. Christine Shieh, Vanderbilt Eye Institute, Nashville, USA

2. Jaime D. Martinez ${ }^{(D)}$, University of Miami Miller School of Medicine, Miami, USA Any reports and responses or comments on the article can be found at the end of the article. 


\section{Keywords}

Bullous pemphigoid, cicatrizing conjunctivitis, autoimmune blistering

disorders, conjunctival granuloma, case series

gateway.

Corresponding author: Sayan Basu (sayanbasu@lvpei.org)

Author roles: Kate A: Data Curation, Formal Analysis, Methodology, Validation, Writing - Original Draft Preparation; Shanbhag S: Investigation, Project Administration, Validation, Visualization, Writing - Review \& Editing; Donthineni PR: Investigation, Project Administration, Validation, Visualization, Writing - Review \& Editing; Basu S: Conceptualization, Funding Acquisition, Methodology, Project Administration, Resources, Supervision, Validation, Writing - Review \& Editing

Competing interests: No competing interests were disclosed.

Grant information: This work was supported by the Hyderabad Eye Research Foundation.

The funders had no role in study design, data collection and analysis, decision to publish, or preparation of the manuscript.

Copyright: $\odot 2021$ Kate A et al. This is an open access article distributed under the terms of the Creative Commons Attribution License, which permits unrestricted use, distribution, and reproduction in any medium, provided the original work is properly cited.

How to cite this article: Kate A, Shanbhag S, Donthineni PR and Basu S. A case series of ocular involvement in bullous pemphigoid: clinical features, management, and outcomes [version 1; peer review: 2 approved] F1000Research 2021, 10:1201

https://doi.org/10.12688/f1000research.75120.1

First published: 25 Nov 2021, 10:1201 https://doi.org/10.12688/f1000research.75120.1 


\section{Introduction}

Autoimmune blistering diseases (AIBD) are a group of disorders where the autoantibodies target antigens within the basement membrane zone (BMZ) of the skin and cause subepidermal blisters. ${ }^{1,2}$ Bullous pemphigoid (BP) is the most common type of AIBD accounting for around $80 \%$ of these blistering entities. ${ }^{1,2}$ The disease usually affects the elderly population ( $>60$ years) and presents with tense, pruritic bullae that affect the flexor regions of the body. ${ }^{1,3,4}$ Direct immunofluorescence (DIF) of skin biopsy samples, shows a linear deposition of C3 and IgG in the BMZ. ${ }^{1,3}$ On indirect immunofluorescence, antibodies against the hemidesmosomal BP antigens 180 (BPAG2) and 230 (BPAG1) are detected in BP. ${ }^{1,3}$ These findings in the context of set clinical criteria help confirm the diagnosis of BP. ${ }^{5}$ The treatment involves long term systemic corticosteroids and non-steroidal agents, and the disease usually has a chronic course with frequent relapses especially on discontinuing the immunosuppressive medications.

In general, mucosal and ocular involvement is rare in BP and its absence is one of the clinical criteria for diagnosis. ${ }^{6}$ Literature on ocular manifestations of BP is sparse and limited to mild conjunctival scarring, dry eye disease and rarely corneal epithelial issues. ${ }^{7-9}$ The current case series aims to describe the demographic details, clinical features, treatment undergone and outcomes of five cases of bullous pemphigoid, which presented with an aggressive form of chronic cicatricial conjunctivitis.

\section{Case series}

A retrospective review of cases with bullous pemphigoid seen between 2017 and 2020 was carried out. Written informed consent for publication and use of their records was obtained from all the patients. Data regarding the baseline demographics, duration of disease prior to presentation and the details of ongoing systemic therapy was collected. All cases underwent a detailed ocular examination that included assessment of visual acuity, slit lamp biomicroscopic examination of the lids, conjunctiva, cornea, and the rest of the anterior segment. This was followed by examination of ocular surface after staining with $2 \%$ fluorescein to document the presence of disruptions in the same. A detailed evaluation of the posterior segment was also carried out. Additionally, data pertaining to the treatment initiated at our institute along with its outcomes was collected.

A total of five cases with bullous pemphigoid were included in the current study. The baseline demographic details, details of systemic disorder, and full treatment details have been presented in Table 1.

\section{Case 1}

A 57-year-old Asian-Indian man who was a businessman by profession, presented to our clinic with complaints of gradual diminution of vision with ocular pain and photophobia. He had developed skin blisters six months prior to presentation and had undergone a skin biopsy for this condition, which confirmed the diagnosis of BP. Although the patient was started on oral immunosuppressive medications (the details of which were not available) he was not compliant with the regimen. At presentation, the uncorrected visual acuity was 20/800 and 20/200 in the right and left eye, respectively. Details of ocular examination have been presented in Table 2. Slit lamp examination revealed significant conjunctival congestion with cicatricial changes in both eyes in the form of symblephara and shortening of the inferior fornices. These fibrotic changes were more pronounced in the lower bulbar and palpebral conjunctiva (Figure 1). On eversion of the upper lids, there was active granulation tissue in both eyes. The cornea in both eyes showed superficial punctate keratitis in the central and inferior areas with filamentary keratitis.

The patient was started on topical therapy along with a maintenance dose of oral steroids $(10 \mathrm{mg} /$ day) (full information in Table 1, Figure 2). He also received three doses of intravenous methyl prednisolone (IVMP) (500 mg), given every three weeks, following which the patient was symptomatically better with improvement in surface inflammation and decrease in the granulation tissue. Five months after presentation, the patient underwent cataract surgery with an intraocular lens as there were no episodes of disease activity in the intervening period. A pulse dose IVMP (500 mg) and cyclophosphamide $(500 \mathrm{mg}$ ) was given prior to the surgery. Postoperatively, the patient was followed up for one year with no disease reactivation noted and vision improving to 20/60. The patient has been planned for cataract surgery in the left eye in the near future.

Case 2

A 36-year-old Asian-Indian man employed in private service, presented with pain, redness, and photophobia in both eyes for six months. He was a diagnosed case of bullous pemphigoid disease based on the results of a skin biopsy and had been prescribed oral prednisolone (10 mg/day). At presentation the corrected visual acuity in the right and left eyes was 20/25 and 20/20, respectively. The inferior conjunctiva showed significant cicatricial changes, while the eversion of the upper lid revealed conjunctival granulomas, which were larger in the right eye (Table 2, Figure 3). The patient was given a pulse dose of IVMP (500 mg) along with topical therapy (full details in Table 1). Oral steroids (prednisolone $10 \mathrm{mg} / \mathrm{day}$ ) were continued, and the patient was closely followed up. 


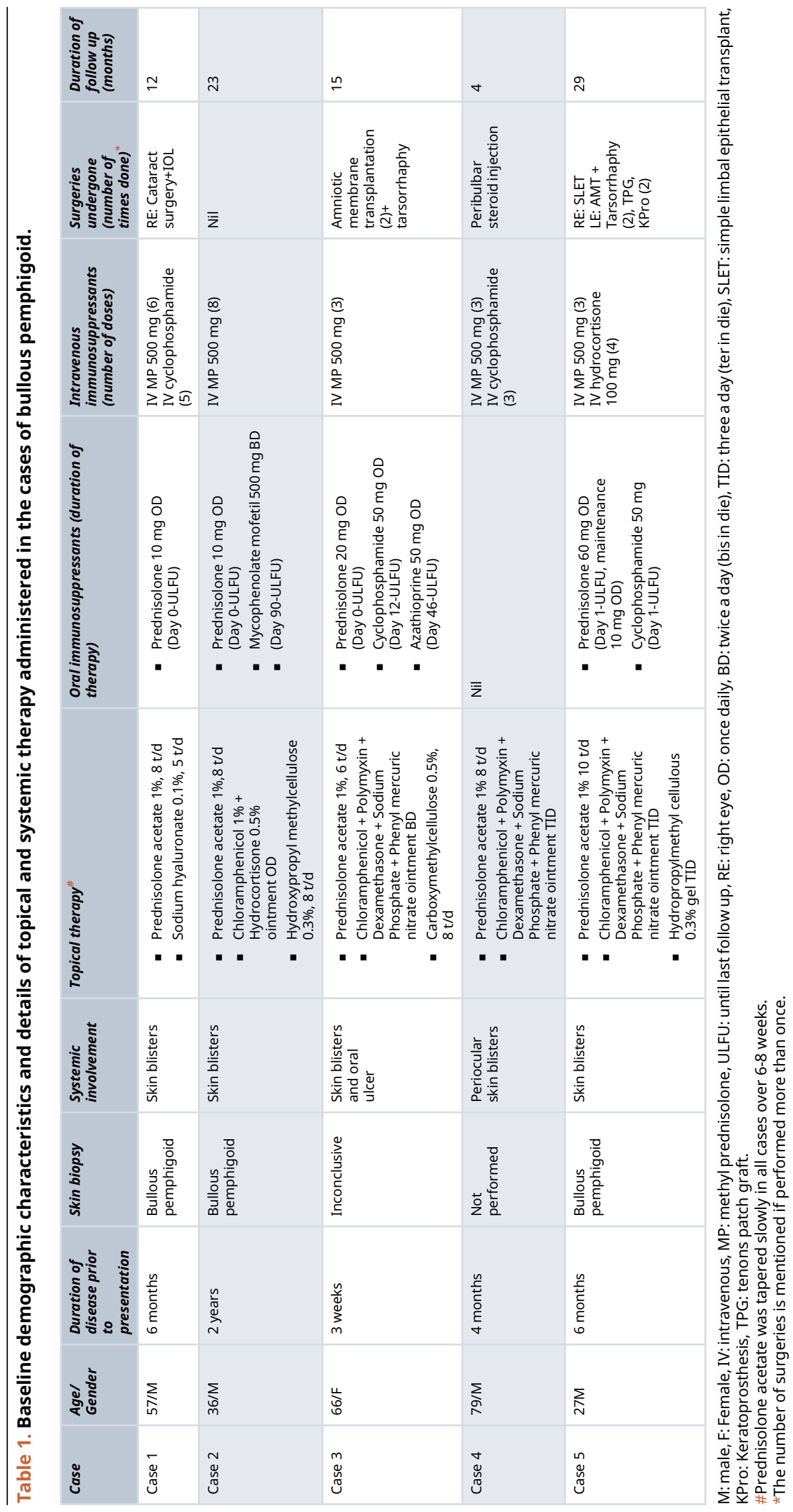




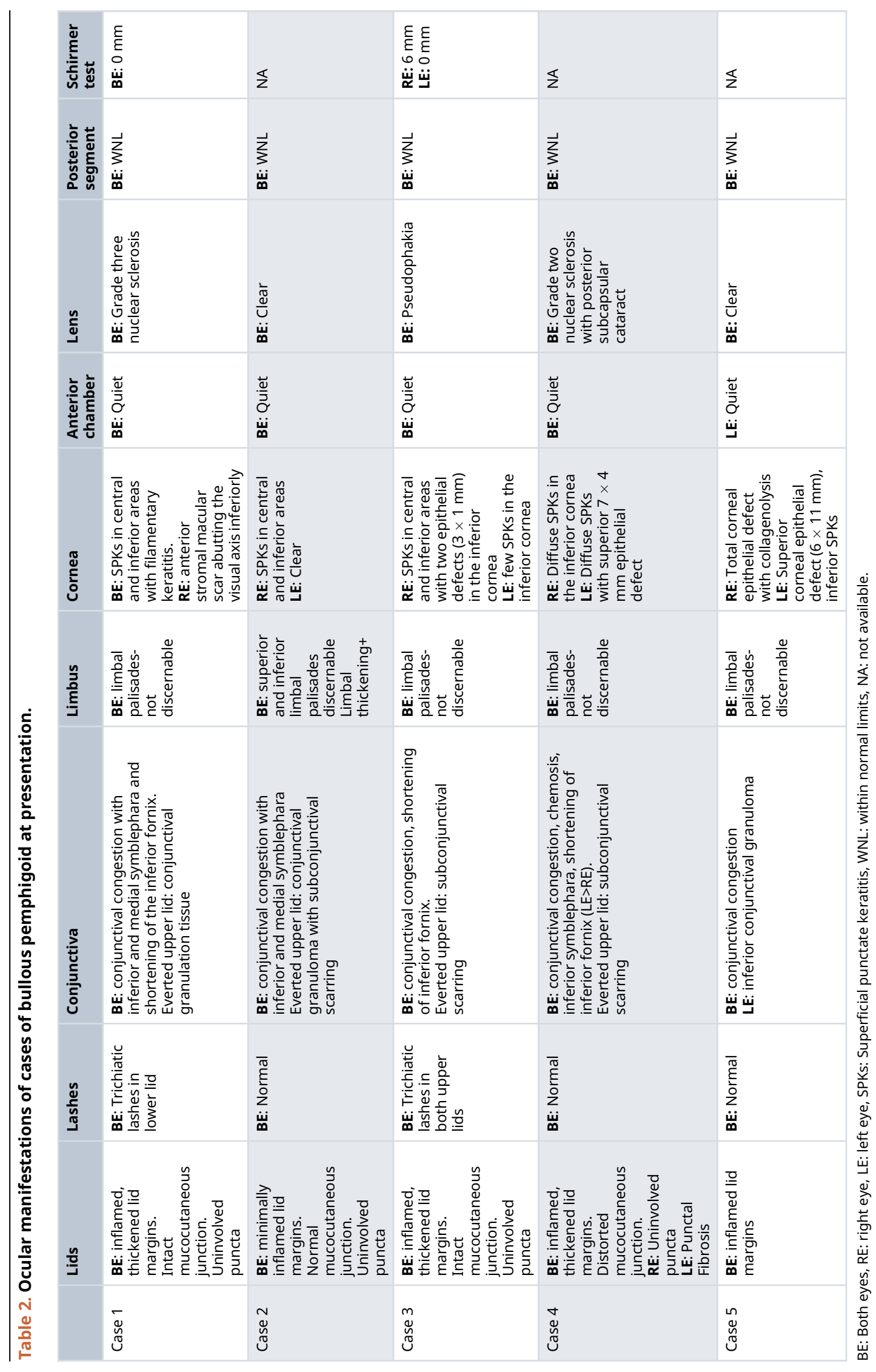




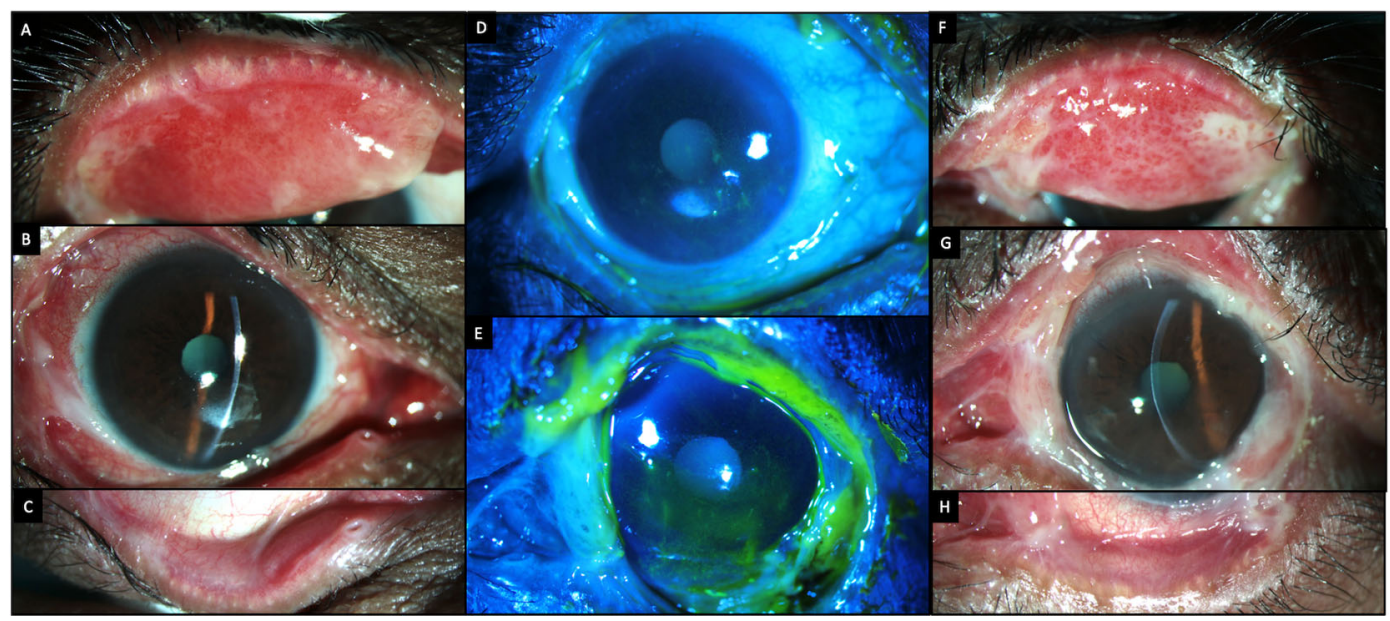

Figure 1. Clinical features at presentation of case 1. (A-C) Slit lamp images of the right eye showing conjunctival congestion, with symblephara laterally, inferiorly and a macular scar in the inferior cornea. Inferior forniceal shortening is also noted. (D, E) Fluorescein-stained images of the right and left eyes respectively showing punctate keratitis with filaments. $(\mathrm{F}-\mathrm{H})$ Slit lamp images of the left eye showing conjunctival congestion, with exuberant granulation tissue and cicatricial changes which are more advanced than those of the right eye.

A significant improvement in the surface inflammation with reduction in the size of the granulomas was noted after 1 week with the topical and systemic immunosuppressants (Figure 4). As the topical steroids were tapered, tacrolimus $0.03 \%$ eye ointment and cyclosporine $0.05 \%$ eye drops were added to the regimen. The patient continued to receive pulse IVMP $(500 \mathrm{mg})$ at every follow up visit which were monthly for three months and two monthly thereafter. Oral mycophenolate mofetil was supplemented three months after presentation. No further disease exacerbation was noted and at the last follow up visit, 23 months after the initial presentation (Figure 2) the granulomas had resolved, and the eyes had no surface inflammation. The patient maintained good vision, with a corrected visual acuity of 20/,20/20 in the right and left eye respectively. Both eyes also had partial limbal stem cell deficiency (LSCD).

\section{Case 3}

A 66-year-old Asian-Indian woman who was a homemaker, had complaints of redness and pain in both eyes for two months. She had oral mucosal ulcers and ruptured blisters over the upper thighs and forearms during the same period (Figure 5). The patient had previously consulted a dermatologist and was suspected to have bullous pemphigoid disease. However, the skin biopsy was not conclusive of this diagnosis. The dermatologist had started the patient on oral prednisolone, which had been tapered to $20 \mathrm{mg}$ by the time of presentation to our department.

On examination, the corrected visual acuity was 20/80 and 20/50 in the right and left eye, respectively. Both eyes showed conjunctival inflammation with inferior forniceal shortening and scarring in the upper tarsal conjunctiva. The right eye had two corneal defects inferiorly (Figure 6, Table 2). Schirmer's test revealed aqueous deficiency (ADDE) in both eyes. A clinical diagnosis of bullous pemphigoid was made based on similarity with other cases. The patient was started on topical and oral immunosuppressants (full details in Table 1).

At the follow up visit after one month, the patient developed new skin lesions for which oral cyclophosphamide was started (Table 1, Figure 2). A sterile corneal melt was noted in the left eye at the same visit and so the patient underwent an amniotic membrane transplantation (AMT), which was repeated after one week as the original membrane disintegrated. The patient received pulse doses of IVMP peri-operatively at weekly intervals, and oral azathioprine was also added to the regimen (Table 1). The disease continued to progress despite the aggressive immunosuppression. Furthermore, the patient did not follow up regularly and one year after the initial presentation, the patient developed total LSCD with a vascularized, scarred cornea and extensive cicatricial changes (Figure 6). The left eye had a dermalised ocular surface.

Case 4

A 79-year-old retired Asian-Indian man, presented with complaints of pain and redness in the eyes with discharge for four months. The patient was not on any topical or systemic therapy prior to presentation. The corrected visual acuity was $20 / 80$ and 20/100 in the right and left eye, respectively. A periocular rash with ruptured blisters was observed in both eyes (Figure 7). Ocular examination revealed thickened lid margins with distorted mucocutaneous junctions. However, no posterior migration was noted. The conjunctiva was inflamed in both eyes with intense cicatricial changes, especially 


\begin{tabular}{|c|c|c|c|c|c|c|c|c|c|c|c|}
\hline \multicolumn{12}{|l|}{ Case 1} \\
\hline \multicolumn{7}{|l|}{$\begin{array}{l}\text { Presented with symblephara, } \\
\text { inferior forniceal shortening } \\
\text { and filamentary keratitis in } B E\end{array}$} & \multicolumn{2}{|c|}{$\begin{array}{c}R E: \\
\text { Phacoemulsification+ } \\
I O L\end{array}$} & & \multicolumn{2}{|c|}{$\begin{array}{c}\text { No disease reactivation } \\
R E 20 / 60 \\
\text { LE planned for cataract surgery }\end{array}$} \\
\hline October 2019 & \multicolumn{2}{|c|}{ November 2019} & \multicolumn{2}{|c|}{ December 2019} & \multicolumn{2}{|c|}{ February 2020} & \multicolumn{2}{|l|}{ March 2020} & August 2020 & \multicolumn{2}{|r|}{ October 2020} \\
\hline $\begin{array}{l}\text { Prednisolone 20mg OD } \\
\text { IV MP } 1 \text { gm }\end{array}$ & \multicolumn{2}{|c|}{$\begin{array}{l}\text { Prednisolone 10mg OD } \\
\text { IV MP } 500 \mathrm{mg} \\
\text { IV CP } 500 \mathrm{mg}\end{array}$} & \multicolumn{2}{|c|}{\begin{tabular}{|l|} 
Prednisolone 10mg OD \\
IV MP $500 \mathrm{mg}(2)^{\sharp}$ \\
IV CP $500 \mathrm{mg}$ \\
\end{tabular}} & \multicolumn{2}{|c|}{\begin{tabular}{|l|} 
Prednisolone 10mg OD \\
IV MP $500 \mathrm{mg}$ \\
IV CP $500 \mathrm{mg}$ \\
\end{tabular}} & \multicolumn{2}{|c|}{$\begin{array}{l}\text { Prednisolone } 10 \mathrm{mg} \text { OD } \\
\text { IV CP } 500 \mathrm{mg}\end{array}$} & \multicolumn{2}{|l|}{$\begin{array}{l}\text { Prednisolone 10mg OD } \\
\text { IV MP } 500 \mathrm{mg} \\
\text { IV CP } 500 \mathrm{mg}\end{array}$} & Prednisolone $10 \mathrm{mg}$ OD \\
\hline \multicolumn{12}{|l|}{ Case 2} \\
\hline $\begin{array}{l}\text { Presented with inferior } \\
\text { conjunctival cicatricial } \\
\text { changes and conjunctival } \\
\text { granulomas }\end{array}$ & & & & & & & & \multicolumn{2}{|r|}{$\begin{array}{l}\text { Subsequent follow up visits } \\
\text { with local ophthalmologist - } \\
\text { continued on oral } \\
\text { medications }\end{array}$} & \multicolumn{2}{|c|}{$\begin{array}{l}\text { Resolution of } \\
\text { granulomas. No surface } \\
\text { inflammation. Partial } \\
\text { LSCD in } B E\end{array}$} \\
\hline April 2018 & \multicolumn{2}{|c|}{ May 2018} & \multicolumn{2}{|c|}{ June 2018} & July 2 & \multicolumn{3}{|c|}{ September 2018} & November 2018 & \multicolumn{2}{|r|}{ March 2020} \\
\hline $\begin{array}{l}\text { Prednisolone } 10 \mathrm{mg} \text { OD } \\
\text { IV MP } 500 \mathrm{mg}\end{array}$ & \multicolumn{2}{|c|}{\begin{tabular}{|l} 
Prednisolone 10mg OD \\
IV MP $500 \mathrm{mg} \mathrm{(3)}$ \\
\end{tabular}} & \multicolumn{2}{|c|}{\begin{tabular}{l|} 
Prednisolone $10 \mathrm{mg}$ OD \\
IV MP $500 \mathrm{mg}$ \\
\end{tabular}} & \multicolumn{2}{|c|}{$\begin{array}{l}\text { Prednisolone 10mg OD } \\
\text { MMF 500mg BD } \\
\text { IV MP 500 mg } \\
\end{array}$} & \multicolumn{2}{|c|}{$\begin{array}{l}\text { Prednisolone } 10 \mathrm{mg} \text { OD } \\
\text { MMF } 500 \mathrm{mg} \text { BD } \\
\text { IV MP } 500 \mathrm{mg}\end{array}$} & $\begin{array}{l}\text { Prednisolone 10mg OD } \\
\text { MMF } 500 \mathrm{mg} \text { BD } \\
\text { IV MP } 500 \mathrm{mg}\end{array}$ & \multicolumn{2}{|r|}{$\begin{array}{l}\text { Prednisolone 10mg OD } \\
\text { MMF 500mg BD }\end{array}$} \\
\hline \multicolumn{12}{|l|}{ Case 3} \\
\hline \multicolumn{5}{|c|}{$\begin{array}{l}\text { Presented with shortening of inferior } \\
\text { fornices and ADDE in BE, corneal } \\
\text { epithelial defects in the RE }\end{array}$} & $\begin{array}{l}\text { LE: Sterile } \\
\text { noted, } A M 7 \\
\text { Tarsorrhap }\end{array}$ & & $\begin{array}{r}\text { Disea } \\
\text { im } \\
\text { irreg }\end{array}$ & $\begin{array}{l}\text { epros } \\
\text { unosi } \\
\text { larpa }\end{array}$ & $\begin{array}{l}\text { tession despite } \\
\text { uppression+ } \\
\text { tient follow up }\end{array}$ & & $\begin{array}{l}\text { tal } L S C D \text {, extensive } \\
\text { tricial changes in } B E\end{array}$ \\
\hline August 2019 & & & & & Septemb & & & & & & Tovember 2020 \\
\hline $\begin{array}{l}\text { Prednisolone 20mg OD } \\
\text { IV MP } 1 \mathrm{gm}\end{array}$ & & & & & $\begin{array}{l}\text { rednisolone } \\
\text { yclophospha } \\
\text { zathioprine } \\
\text { V MP } 500 \mathrm{~m}\end{array}$ & & & & & \begin{tabular}{|l} 
Prednis \\
Cyclop \\
Azathic
\end{tabular} & $\begin{array}{l}\text { isolone } 20 \mathrm{mg} \text { OD } \\
\text { phosphamide 50mg OD } \\
\text { ioprine } 50 \mathrm{mg} \text { OD }\end{array}$ \\
\hline Case 4 & & & & & & & & & & & \\
\hline $\begin{array}{l}\text { Presented with a periocular } \\
\text { shortening of inferior fornices in } \\
\text { corneal epithelial defe }\end{array}$ & $\begin{array}{l}\text { blisters, } \\
\text { BE. LE had a } \\
\text { fect }\end{array}$ & & & & & & & & & $\begin{array}{l}\text { Persistent } \\
\text { eribulbar }\end{array}$ & $\begin{array}{l}\text { nt disease activity noted. } \\
\text { rtriamcinolone acetonide } \\
\text { given in } B E\end{array}$ \\
\hline February 2021 & & & & & Apri & & & & & & $\overrightarrow{\text { May } 2021}$ \\
\hline $\begin{array}{l}\text { IV MP } 500 \mathrm{mg} \\
\text { IV CP } 500 \mathrm{mg}\end{array}$ & & & & & $\begin{array}{l}\text { IV MP } 5 \\
\text { IV CP } 5\end{array}$ & & & & & & $\begin{array}{l}\text { IV MP } 500 \mathrm{mg} \\
\text { IV CP } 500 \mathrm{mg}\end{array}$ \\
\hline Case 5 & & & & & & & & & & & \\
\hline $\begin{array}{l}\text { Presented with a total corneal } \\
\text { defect with collagenolysis in } R E \\
\text { superior corneal epithelial de } \\
\text { inferior conjunctival granu }\end{array}$ & $\begin{array}{l}\text { lepithelial } \\
\text { E. LE had a } \\
\text { lefect with } \\
\text { ulomas }\end{array}$ & & $\begin{array}{l}\text { ithelial } \\
\text { bility } \\
\text { 'done }\end{array}$ & $\begin{array}{r}L E: \\
-T P G\end{array}$ & $\begin{array}{l}\text { epithelial ins } \\
\text { +Tarsorrhap }\end{array}$ & & $\begin{array}{r}\text { LE:Decompensa } \\
\text { cornea-KPro perfo }\end{array}$ & & $\begin{array}{r}\text { KPro extruded } \\
\text { Repeat KPro perfot }\end{array}$ & ed & $\begin{array}{l}\text { Stable KPro } \\
\text { No disease } \\
\text { reactivation }\end{array}$ \\
\hline September 2017 & Novem & & & February & 2018 & & vember 2018 & & October 2019 & & March 2020 \\
\hline $\begin{array}{l}\text { RE SLET LE AMT+tarsorrhaph } \\
\text { IV MP 500mg (2) } \\
\text { Prednisolone } 60 \mathrm{mg} \text { OD } \\
\text { Cyclophosphamide } 50 \mathrm{mg} \text { OD }\end{array}$ & $\begin{array}{l}\text { Prednis } \\
\text { OD } \\
\text { Cyclop } \\
\text { mg OD }\end{array}$ & $\begin{array}{l}\text { ie } 10 \mathrm{~m} \\
\text { hamid }\end{array}$ & & $\begin{array}{l}\text { Prednisolo } \\
\text { OD } \\
\text { Cyclophos } \\
\text { mg OD }\end{array}$ & $\begin{array}{l}\text { ae } 10 \mathrm{mg} \\
\text { phamide } 50\end{array}$ & $\begin{array}{l}\text { Predn } \\
\text { OD } \\
\text { Cyclc } \\
\text { mg O }\end{array}$ & $\begin{array}{l}\text { Inisolone } 10 \mathrm{mg} \\
\text { lophosphamide } 50 \\
\text { OD }\end{array}$ & & \begin{tabular}{|l|} 
Prednisolone $10 \mathrm{mg}$ OD \\
Cyclophosphamide $50 \mathrm{~m}$ \\
IV hydrocortisone $100 \mathrm{~m}$ \\
(4)
\end{tabular} & $\begin{array}{l}\mathrm{mg} \text { OD } \\
\mathrm{mg} B D\end{array}$ & $\begin{array}{l}\text { Prednisolone } 10 \mathrm{mg} \\
\text { OD } \\
\text { Cyclophosphamide } 50 \\
\text { mg OD }\end{array}$ \\
\hline
\end{tabular}

Figure 2. Timeline of all cases detailing the various immunosuppressive medications and interventions performed. BE: both eyes, RE: right eye, LE: left eye, IV: intravenous, MP: methyl prednisolone, CP: cyclophosphamide, TPG: tenons patch graft, AMT: amniotic membrane transplantation, SLET: simple limbal epithelial transplant, LSCD: limbal stem cell deficiency, KPro: keratoprosthesis. The numbers in brackets indicate the number of doses, if more than one was given.

in the inferior fornices, which showed shortening with symblephara. These changes were more pronounced in the left eye where the inferior fornix was obliterated. Both eyes had diffuse superficial punctate keratitis (SPKs) with a corneal epithelial defect in the left eye (Table 2, Figure 8). The patient received a pulse dose of IVMP (500 mg) with IV cyclophosphamide $(500 \mathrm{mg}$ ) along with topical medications (full details in Table 1, Figure 2). A decrease in the size of the epithelial defect was noted after 2 months, but the surface inflammation continued to persist and so the patient received another pulse dose of IVMP and cyclophosphamide. Still, a satisfactory response was not observed and so the patient received a peribulbar injection of $1 \mathrm{ml}$ of $4 \%$ triamcinolone acetonide in both eyes, 3 months after the initial presentation. The patient was lost to follow up after the procedure.

Case 5

A 27-year-old Asian-Indian man, a farmer by profession, presented with complaints of gross decrease in vision in the right eye for two weeks. He gave a history of skin blisters six months prior to presentation for which a skin biopsy was carried out and a diagnosis of bullous pemphigoid was confirmed. Systemic immunosuppressive agents were started (full details in Table 1, Figure 2). The visual acuity in the right eye was perception of light while that in the left eye was 20/50. On slit lamp examination, both eyes had significant conjunctival congestion. The right eye showed a total corneal 


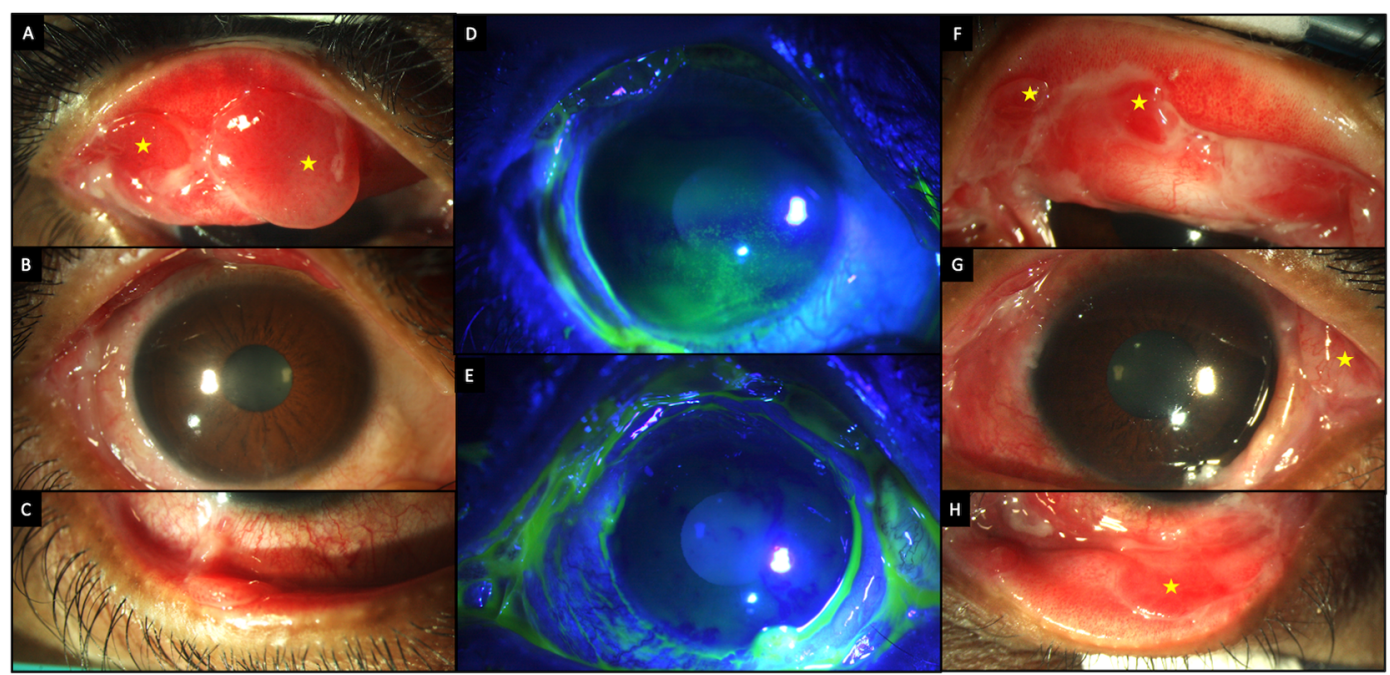

Figure 3. Clinical features at presentation of case 2. (A-C) Slit lamp images of the right eye showing conjunctival congestion, with two conjunctival granulomas superiorly (yellow stars) and symblephara inferiorly. (D, E) Fluoresceinstained images of the right and left eyes respectively showing punctate keratitis in the right eye. (F-H) Slit lamp images of the left eye showing conjunctival granulomas (yellow stars), with a symblepharon laterally. ${ }^{19}$

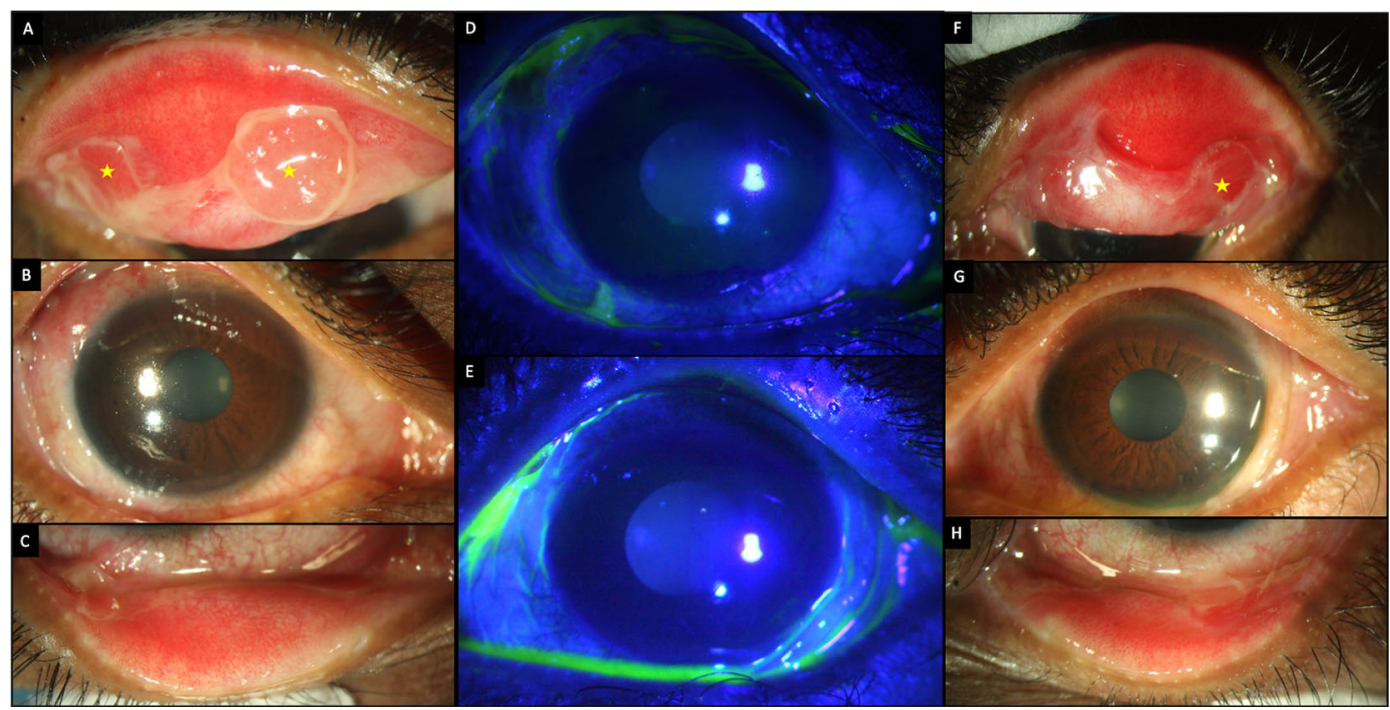

Figure 4. Improvement in the clinical features after two doses of pulse IV methyl prednisolone in case 2. (A-C) Slit lamp images of the right eye showing decrease in congestion with decreased size of the granulomas (yellow stars). (D, E) Fluorescein stained images of the right and left eyes respectively showing a stable surface with no corneal staining. (F-H) Images of the left eye showing decreased inflammation and smaller granulomas (yellow stars).

epithelial defect with collagenolysis. The left eye had a superior corneal epithelial defect with inferior conjunctival granulomas (Figure 9). To address the issues in both eyes, the patient underwent an allogenic simple limbal epithelial transplant from a cadaveric donor, in the right eye and an AMT in the left eye. Postoperatively, the patient was started on oral steroids and cyclophosphamide (full details in Table 1). The right eye surface stabilized over two months and was completely epithelialized with a pannus formation. The left eye continued to have epithelial instability and the patient underwent a repeat AMT and a tenons patch graft for the same. Eventually the left eye developed a decompensated cornea and a keratoprosthesis (KPro) was carried out 13 months after the initial presentation. The visual acuity improved to 20/30 and the prosthesis was stable. However, one year after the surgery, extrusion of the KPro was noted and the patient underwent a repeat KPro (Figure 9). The second KPro was stable until the last follow up which was 4.5 months after the procedure. The patient had a vision of 20/100 in the left eye. No relapse of the systemic disease was seen, and the patient 


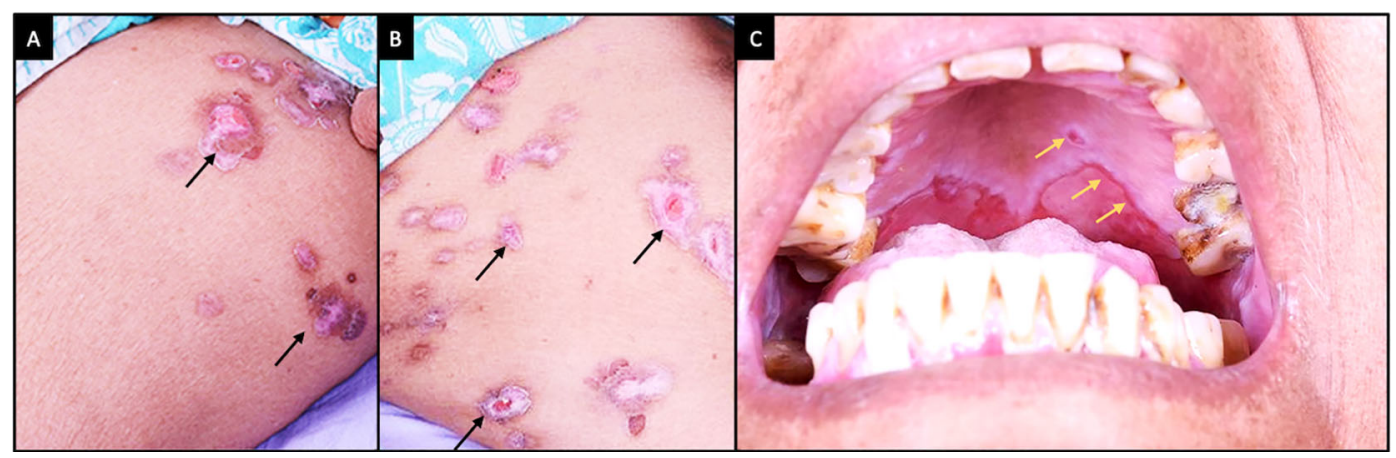

Figure 5. Systemic clinical features at presentation of case 3. (A, B) Ruptured blisters over the flexor aspect of the thighs (black arrows). (C) Oral ulcers over the hard and soft palate (yellow arrows).

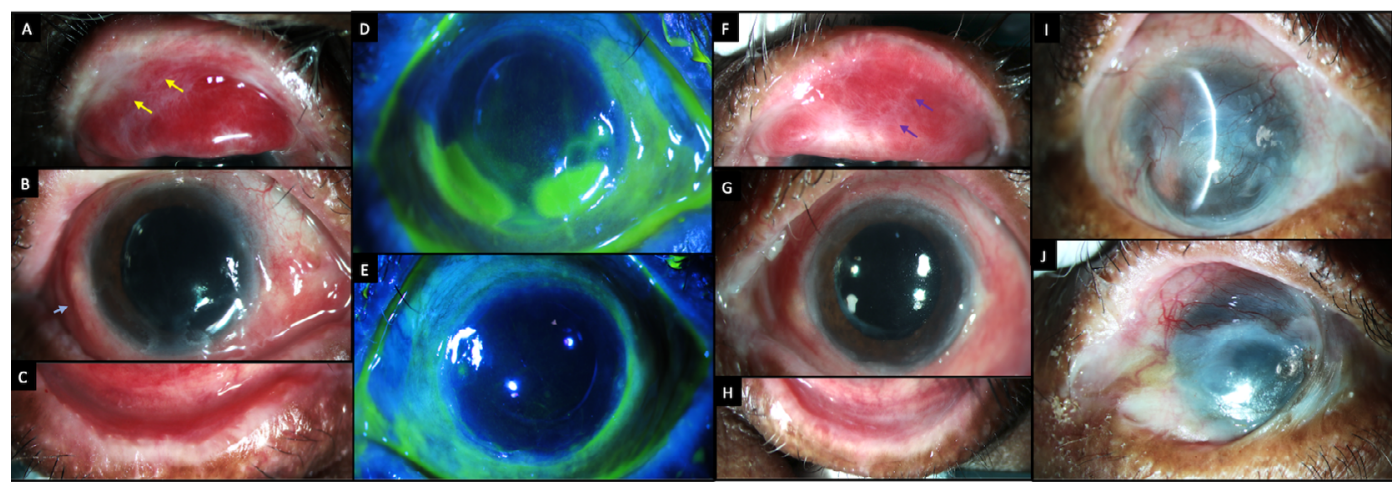

Figure 6. Ocular clinical features at presentation of case 3. (A-C) Slit lamp images of the right eye showing conjunctival congestion, with tarsal scarring superiorly (yellow arrows), limbal thickening (blue arrow) and inferior forniceal shortening. (D, E) Fluorescein-stained images of the right and left eyes respectively showing two epithelial defects in the inferior cornea in the right eye. (F-H) Slit lamp images of the left eye showing tarsal scarring (violet arrows) and inferior forniceal shortening. (I, J) Images of the right and left eye respectively after one year of follow up, showing total limbal stem cell deficiency with a pannus over the cornea. Left eye shows a dermalised ocular surface.

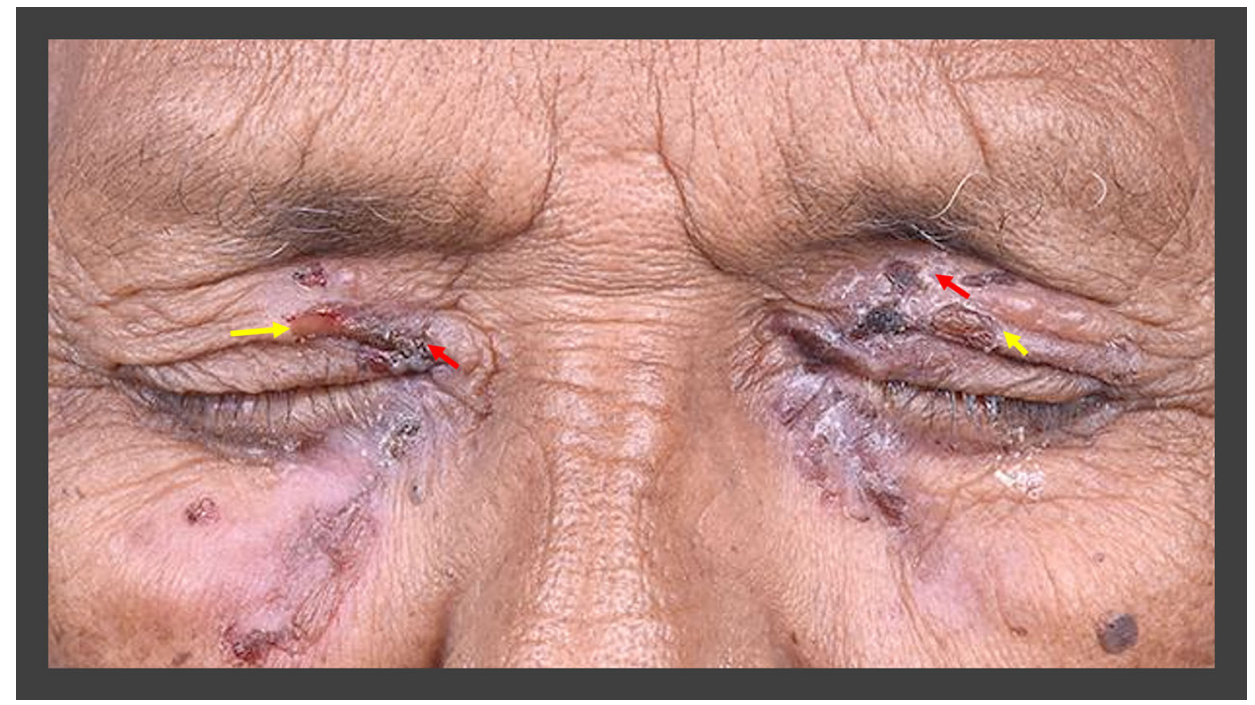

Figure 7. Periocular blisters around both eyes in case 4. Some of the blisters have ruptured (yellow arrows) while the others are crusted over (red arrows). 


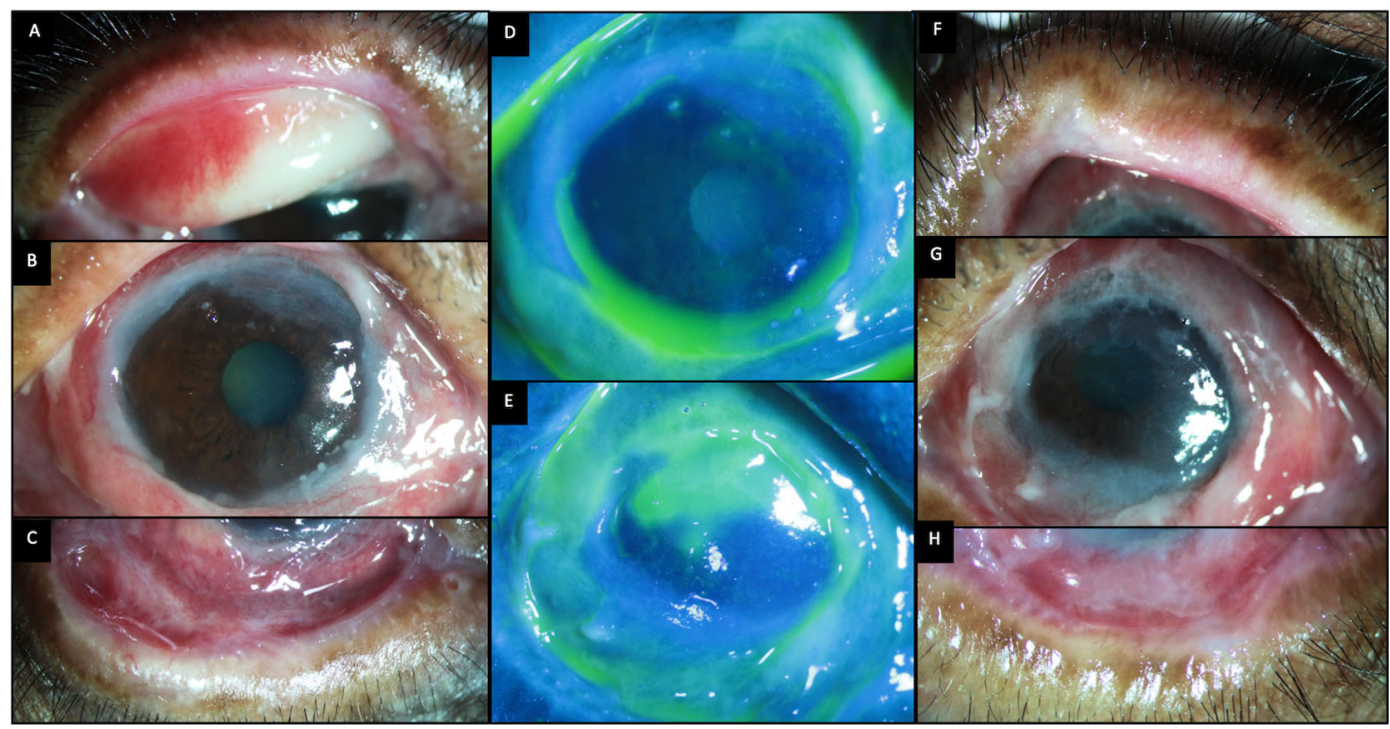

Figure 8. Ocular clinical features at presentation of case 4. (A-C) Slit lamp images of the right eye showing thickened distorted mucocutaneous junctions, tarsal scarring superiorly and inferior forniceal shortening with symblephara. (D, E) Fluorescein-stained images of the right and left eyes respectively showing diffuse punctate keratitis in the right eye and a superior epithelial defect in the left eye. (F-H) Images of the left eye showing thickened distorted mucocutaneous junctions and obliteration of the inferior fornix. The bulbar conjunctiva also shows thickened fibrotic changes.

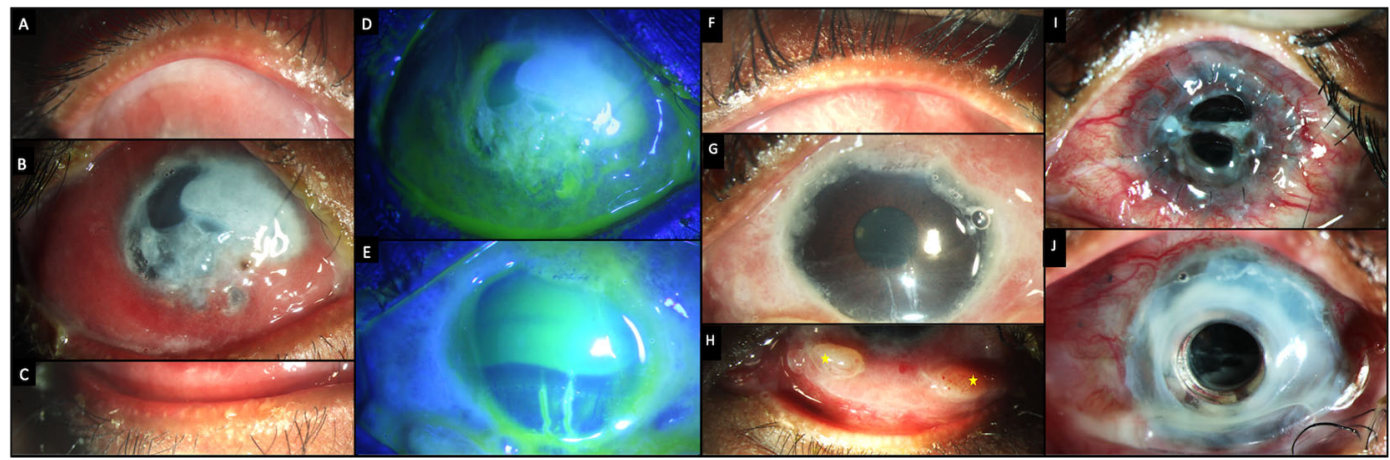

Figure 9. Clinical features at presentation of case 5. (A-C) Slit lamp images of the right eye showing congestion and chemosis with significant collagenolysis in the cornea. (D, E) Fluorescein-stained images of the right and left eyes respectively showing a total epithelial defect in the right eye and a superior epithelial defect in the left eye. (F-H) Images of the left eye showing intense fibrotic changes in the conjunctiva with two granulomas inferiorly (yellow stars). (I) Slit lamp image of the left eye with an extruded Keratoprosthesis. (J) Image of the same eye following a repeat keratoprosthesis, with a skirt amniotic membrane around the prosthesis. ${ }^{19}$

was on topical (prednisolone acetate $1 \%$, tacrolimus $0.03 \%$ ointment) and systemic immunosuppression (prednisolone $10 \mathrm{mg}$ and cyclosporine $50 \mathrm{mg}$ ).

\section{Discussion}

Bullous pemphigoid disease is the most common subepidermal blistering disorder, which predominantly affects cutaneous tissue. $^{3}$ Though ocular involvement is rare, a few reports of early cicatricial changes exist in literature. ${ }^{4,7-9}$ In the current series, all five cases presented with advanced disease and extensive conjunctival fibrotic changes, which were more severe in the inferior bulbar and palpebral conjunctiva. Corneal changes were also more localized to the inferior cornea suggesting a degree of exposure keratopathy, due to the inferior cicatricial changes, contributing to the disease process. The response to therapy was variable and usually correlated with the systemic response. This was seen in case 3, where the skin lesions continued to progress despite immunosuppression and a similar pattern of worsening of the 
ocular surface was also observed. This is in contrast to the first two cases where a good control of ocular inflammation was observed with no exacerbations of the systemic disease.

Although BP is considered to be a disease of the elderly, 2/5 cases in the current series presented at an earlier age. A few series have described the clinical course of BP in patients younger than 60 years and have reported a more aggressive form of the disease with higher levels of circulating autoantibodies. ${ }^{10,11}$ A greater involvement of the head and neck regions has also been noted in this subgroup of population. ${ }^{10,11}$ In the present series, $4 / 5$ cases were male, which is in contrast to the female preponderance associated with BP. ${ }^{4,12,13}$ A reversal of this trend of female predominance, with increased incidence of BP in males with advancing age has also been described. ${ }^{12}$ Ocular findings of BP described in literature include ADDE, early tarsal scarring and pannus formation. ${ }^{7,9}$ Only one case with symblephara and inferior forniceal shortening has been reported so far. ${ }^{7}$ Kiyokawa et al reported an unusual case with corneal involvement in the absence of conjunctival involvement. ${ }^{8}$ The findings in the cases described in our study represent a more aggressive form of presentation with advanced cicatricial changes and granuloma formation and have not been reported previously. The corneal involvement seen in the present series could be secondary to the inflammatory mediators over the ocular surface, the ADDE, the irregular ocular surface itself or due to the LSCD that developed over the course of the disease.

Severe, progressive fibrotic conjunctival changes with concurrent LSCD and ADDE are more commonly associated with mucous membrane pemphigoid (MMP). Traditionally patients with MMP have active or scarred lesions in the oral and nasopharyngeal mucosa with occasional cutaneous involvement. ${ }^{6}$ This contrasts with BP, wherein the mucosal involvement is infrequent, and patients typically present with tense, pruritic skin blisters. Differentiating the two entities in the absence of these classical systemic findings poses a challenge because the findings on DIF for both entities are similar with linear antibody deposits in the BMZ. ${ }^{6,14}$ Therefore, in cases of isolated ocular involvement further immunopathologic workup such as DIF studies on salt-split skin, enzyme-linked immunosorbent assay (ELISA) for specific autoantibodies, etc. may be required to distinguish the two blistering disorders. ${ }^{6}{ }^{14}$ The clinical features of antiepiligrin variant of MMP closely mimic those of case 3 presented in this report, can be considered a differential in such cases. The presence of antibodies against laminin 5 in patients sera detected by Western Blot and immunoprecipitation tests are used to confirm the diagnosis of this entity. ${ }^{15}$

Systemic immunosuppressive therapy forms the mainstay of therapy in cases of BP, however a few cases of management with local immunosuppressive agents have also been reported. ${ }^{3,14}$ Treatment of localized cutaneous involvement with potent topical steroids such as clobetasol propionate has shown good results. ${ }^{1,3}$ A similar regimen can be adopted in isolated ocular involvement with topical or depot injections of potent corticosteroids as seen in case 4 of our series. In cases with widespread involvement administration of systemic corticosteroids is recommended. This can be given orally or in a pulsed intravenous manner. ${ }^{14}$ The advantages of the latter include a faster response rate with fewer long term side effects. ${ }^{14,16,17}$ All patients in the current series received a pulse therapy of IVMP either in isolation or in combination with cyclophosphamide. A maintenance dose of oral prednisolone was also a part of therapy in 4/5 cases. Several steroid sparing immunosuppressive agents such as azathioprine, mycophenolate mofetil, cyclophosphamide have been studied in BP, and have comparable response rates. ${ }^{18-20}$ These agents are usually added when adequate response with the maintenance steroid dose is not observed or when an increased need for pulse doses is required. Other modalities of therapy that have been used in the management of BP include dapsone, tetracyclines, biologics, immunoglobulins, plasmapheresis, etc. and these maybe effective in recalcitrant cases. ${ }^{1,14}$

In conclusion, ocular involvement in cases of BP is rare and usually subtle. In the current study, the patients presented with an advanced form of the disease characterized by severe cicatricial and granulomatous changes of the conjunctiva with LSCD, ADDE and corneal epithelial instability. Diagnosis of BP is based on a combination of classical skin blisters and a confirmatory immunofluorescence on skin biopsy. In the absence of these cutaneous findings, MMP is a close differential and additional investigations maybe required to differentiate the two diseases. Long term immunosuppression is required in the management of BP and the use of pulse IVMP with systemic steroid sparing immunosuppressive agents is usually associated with good response rates. Aggressive immunosuppression is required in cases that present with advanced ocular findings in order to preserve the visual function and to retard the chronic sequelae.

\section{Data availability}

All data underlying the results are available as part of the article and no additional source data is required.

\section{Consent}

Written informed consent was obtained from all the patients for publication of this case report and accompanying images. 
1. Daniel BS, Murrell DF: Review of autoimmune blistering diseases: the Pemphigoid diseases. J Eur Acad Dermatol Venereol. 2019; 33: 1685-1694.

PubMed Abstract | Publisher Full Text

2. Di Zenzo G, Marazza G, Borradori L: Bullous pemphigoid: physiopathology, clinical features and management. Adv Dermatol. 2007; 23: 257-288.

PubMed Abstract | Publisher Full Text

3. Bernard P, Antonicelli F: Bullous Pemphigoid: A Review of its Diagnosis, Associations and Treatment. Am J Clin Dermatol. 2017; 18: 513-528.

PubMed Abstract | Publisher Full Text

4. Ekong AS, Foster CS, Roque MR: Eye involvement in autoimmune blistering diseases. Clin Dermatol. 2001; 19: 742-749.

PubMed Abstract | Publisher Full Text

5. Vaillant L, Bernard P, Joly P, et al.: Evaluation of clinical criteria for diagnosis of bullous pemphigoid. French Bullous Study Group. Arch Dermatol. 1998; 134: 1075-1080.

PubMed Abstract | Publisher Full Text

6. $\mathrm{Xu} \mathrm{H}-\mathrm{H}$, Werth VP, Parisi E, et al.: Mucous Membrane Pemphigoid. Dent Clin North Am. 2013; 57: 611-630.

PubMed Abstract | Publisher Full Text | Free Full Text

7. Venning VA, Frith PA, Bron AJ, et al.: Mucosal involvement in bullous and cicatricial pemphigoid. A clinical and immunopathological study. BrJ Dermatol. 1988; 118: 7-15. Publisher Full Text

8. Kiyokawa C, Fujito S, Mori O, et al.: Bullous pemphigoid showing unusual ocular changes. BrJ Dermatol. 1998; 139: 693-696. Publisher Full Text

9. Tan JCK, Tat LT, Francis KB, et al.: Prospective study of ocular manifestations of pemphigus and bullous pemphigoid identifies a high prevalence of dry eye syndrome. Cornea. 2015 34: 443-448.

Publisher Full Text

10. Bourdon-Lanoy $E$, Roujeau J-C, Joly $P$, et al.: Bullous pemphigoid in young patients: a retrospective study of $\mathbf{7 4}$ cases. Ann Dermatol Venereol. 2005; 132: 115-122. PubMed Abstract | Publisher Full Text

11. Zanella RR, Xavier TA, Tebcherani AJ, et al.: Bullous pemphigoid in younger adults: three case reports. An Bras Dermatol. 2011; 86:
355-358.

PubMed Abstract | Publisher Full Text

12. Kridin K, Ludwig Rj: The Growing Incidence of Bullous Pemphigoid: Overview and Potential Explanations. Front Med (Lausanne). 2018; 5: 220.

Publisher Full Text

13. Kulthanan K, Chularojanamontri L, Tuchinda P, et al.: Prevalence and clinical features of Thai patients with bullous pemphigoid. Asian Pac J Allergy Immunol. 2011; 29: 66-72. PubMed Abstract

14. Khandpur S, Verma P: Bullous pemphigoid. Indian J Dermatol Venereol Leprol. 2011; 77: 450-455. Publisher Full Text

15. Nischler C, Sadler E, Lazarova Z, et al.: Ocular involvement in antiepiligrin cicatricial pemphigoid. Eur J Ophthalmol. 2006; 16: 867-869.

PubMed Abstract | Publisher Full Text

16. Shahidi-Dadras M, Karami A, Toosy $P$, et al.: Pulse versus oral methylprednisolone therapy in pemphigus vulgaris. Arch Iran Med. 2007; 10: 1-6.

Reference Source | PubMed Abstract

17. Sacchidanand S, Hiremath NC, Natraj HV, et al.: Dexamethasonecyclophosphamide pulse therapy for autoimmunevesiculobullous disorders at Victoria hospital, Bangalore. Dermatol Online J. 2003; 9: 2. Publisher Full Text

18. Sticherling $M$, Franke A, Aberer E, et al.: An open, multicentre, randomized clinical study in patients with bullous pemphigoid comparing methylprednisolone and azathioprine with methylprednisolone and dapsone. Br J Dermatol. 2017; 177 1299-1305. Publisher Full Text

19. Vazirani J, Donthineni P, Goel S, et al.: Chronic cicatrizing conjunctivitis. Indian J. Ophthalmol. November 2020; 68(11) 2349-2355.

20. Meurer M: Immunosuppressive therapy for autoimmune bullous diseases. Clin Dermatol. 2012; 30: 78-83. PubMed Abstract | Publisher Full Text 


\section{Open Peer Review}

\section{Current Peer Review Status:}

\section{Version 1}

Reviewer Report 24 January 2022

https://doi.org/10.5256/f1000research.78945.r101150

(C) 2022 Martinez J. This is an open access peer review report distributed under the terms of the Creative Commons Attribution License, which permits unrestricted use, distribution, and reproduction in any medium, provided the original work is properly cited.

\section{Jaime D. Martinez}

Department of Ophthalmology, Bascom Palmer Eye Institute, University of Miami Miller School of Medicine, Miami, FL, USA

Excellent review of cases. Pemphigoid is a complex disease to treat, and the importance of ocular surface details needs to be emphasized like in this article.

\section{Comments:}

1. Change the word "non steroidal" to "anti-inflammatory or immunosuppression" Introduction first paragraph.

2. Case 2 last paragraph missing number 20 on $20 / 20$

3. Can you add details on how the patient responded to triamcinolone injection on case 4.

Is the background of the cases' history and progression described in sufficient detail? Yes

Are enough details provided of any physical examination and diagnostic tests, treatment given and outcomes?

Yes

Is sufficient discussion included of the importance of the findings and their relevance to future understanding of disease processes, diagnosis or treatment?

Yes

Is the conclusion balanced and justified on the basis of the findings? Yes 
Competing Interests: No competing interests were disclosed.

Reviewer Expertise: Ocular surfaces disease

I confirm that I have read this submission and believe that I have an appropriate level of expertise to confirm that it is of an acceptable scientific standard.

Author Response 27 Jan 2022

\section{Sayan Basu}

We would like to thank the reviewer for reading and commenting on our submission. The following comments have been addressed in the manuscript.

1. Change the word "non steroidal" to "anti-inflammatory or immunosuppression" Introduction first paragraph.

The required change has been made

2.Case 2 last paragraph missing number 20 on 20/20

Thank you for pointing this out. We have corrected the typographical error.

3.Can you add details on how the patient responded to triamcinolone injection on case 4 The patient unfortunately did not follow up after the triamcinolone injection and so the response to therapy is not known

Competing Interests: The authors have no competing interests to disclose

Reviewer Report 13 January 2022

\section{https://doi.org/10.5256/f1000research.78945.r101151}

(C) 2022 Shieh C. This is an open access peer review report distributed under the terms of the Creative Commons Attribution License, which permits unrestricted use, distribution, and reproduction in any medium, provided the original work is properly cited.

\section{Christine Shieh}

Department of Ophthalmology and Visual Sciences, Vanderbilt Eye Institute, Nashville, TN, USA

\section{Summary of the Paper}

The authors present a case series of 5 patients with advanced ocular involving bullous pemphigoid (BP), a rare and sparsely characterized entity. The goal was to describe the ocular features of these patients, treatment course, and outcomes of these patients.

All patients were treated with systemic immunosuppression and steroid-sparing immunomodulatory therapy. All patients but one (case 4) had at least 1 year follow-up. Case 1 \& 2 
are examples of advanced ocular involving patients with good clinical outcomes with systemic immunosuppressive therapy.

Cases 3-5 had poorer outcomes and required more invasive interventions. Case 3 developed corneal melt refractory to medical therapy and required two amniotic membrane transplants. Her course was also complicated by irregular clinical follow-up which likely impacted her clinical course. At 1 year, she had complete limbal stem cell deficiency.

Case 4 had peribulbar triamcinolone administered but was lost to follow-up subsequently. The clinical outcome from this case is unknown at this time. Case 5 required an allogenic limbal transplant OD and amniotic membrane OS. While the right eye stabilized, the left eye endured a complicated course requiring repeat amniotic membrane, followed by K-Pro which was complicated by extrusion and required a repeat KPro.

The case series accomplished its goal of presenting a variety of advanced cases with ocular involving BP, showcasing different clinical outcomes. Given that there are few reports of ocular involvement and most describe just early cicatricial changes, this series is very valuable for clinicians in understanding and treating ocular surface disease in patients with BP.

\section{Is the background of the cases' history and progression described in sufficient detail?}

Yes - Each of the cases are described in good detail and well-complemented by high-quality slit lamp photos. The history and clinical course/progression were further complemented by an organized timeline (Figure 2).

Are enough details provided of any physical examination and diagnostic tests, treatment given, and outcomes?

Yes - the authors are very thorough in describing the various examination findings for each patient. There are good quality photos for each of the patients. Table 2 organizes each of the patient's anterior segment exam findings very clearly. As for the treatment course, Figure 2 lays out a nice timeline for each of the 5 patients showing different treatment modalities and the clinical outcome.

\section{Is sufficient discussion included of the importance of the findings and their relevance to future understanding of disease processes, diagnosis, or treatment?}

Yes - They do a great job of showing how ocular BP can manifest in such advanced stages. All 5 cases of advanced ocular involvement of BP required systemic immunosuppression with steroids and then steroid-sparing immunomodulators. In their discussion, they clearly state that advanced cases like these require systemic immunosuppression long-term.

Case 3 \& 5 presented with epithelial defects and had poorer outcomes/required more invasive interventions than Cases $1 \& 2$. Would love to have the authors include a few sentences in the discussion section about their clinical opinion as to why Cases $3 \& 5$ had poorer outcomes. Presumably, this was due to the degree of limbal stem cell deficiency?

\section{Is the conclusion balanced and justified on the basis of the findings?}


Yes - they make a well supported conclusion that patients require quick immunosuppressive therapy and long term maintenance therapy as well. Patients $1 \& 2$ were successfully treated this way, and the other patients required more invasive interventions beyond systemic medical therapy.

Is the background of the cases' history and progression described in sufficient detail? Yes

Are enough details provided of any physical examination and diagnostic tests, treatment given and outcomes?

Yes

Is sufficient discussion included of the importance of the findings and their relevance to future understanding of disease processes, diagnosis or treatment?

Yes

Is the conclusion balanced and justified on the basis of the findings?

Yes

Competing Interests: No competing interests were disclosed.

I confirm that I have read this submission and believe that I have an appropriate level of expertise to confirm that it is of an acceptable scientific standard.

Author Response 27 Jan 2022

Sayan Basu

Case 3 \& 5 presented with epithelial defects and had poorer outcomes/required more invasive interventions than Cases $1 \& 2$. Would love to have the authors include a few sentences in the discussion section about their clinical opinion as to why Cases 3 \& 5 had poorer outcomes. Presumably, this was due to the degree of limbal stem cell deficiency?

We thank the reviewer for their comments. The progressive disease noted in case 3 was likely due to the non-compliance to the systemic immunosuppressive therapy and the progression of the underlying systemic disease as well. In case 5 the gimbal stem cell deficiency aggravated the epithelial instability and hampered the healing process resulting in repeated episodes of epithelial breakdown. These points have been incorporated within the discussion

Competing Interests: The authors have no competing interests to disclose. 
The benefits of publishing with F1000Research:

- Your article is published within days, with no editorial bias

- You can publish traditional articles, null/negative results, case reports, data notes and more

- The peer review process is transparent and collaborative

- Your article is indexed in PubMed after passing peer review

- Dedicated customer support at every stage

For pre-submission enquiries, contact research@f1000.com 